\title{
Perception, Aspects and Explanation: Some Remarks on Moderate Partisanship ${ }^{i}$
}

\begin{abstract}
Modifying a contrast found in Dixon (2001), Stephen Mumford (2012; 2012a) distinguishes between 'partisan' and 'purist' ways of watching sport. Recognising that the extreme partisan and extreme purist positions do not explain the nature of sports spectatorship, Mumford follows Dixon in adopting the idea of moderate partisanship (any spectator who is neither all-partisan nor all-purist). He outlines three theories of spectatorship designed to address the issue of the relationship between the partisan and the purist ways of viewing sport. The true perception theory regards the moderate fan as able to see the event as it really is, rather than concentrating on an aspect (as the extreme purist and extreme partisan do). The mixture theory is the view that 'the moderate partisan has both partisan and purist perceptions of sport in some mixed way' (2012a: 373). The oscillation theory, which Mumford favours, holds that the moderate sports fan switches or oscillates between competitive (partisan) and aesthetic (purist) ways of watching sport.
\end{abstract}

This paper does not offer an alternative theory to Mumford's account. Instead, it explores the possibility of dissolving the problem. Mumford is troubled by the distinction, and feels that he requires a theory to solve the problem he thinks it raises (and thereby explain the relationship between partisan and purist ways of viewing sport). The idea that purist and partisan ways of viewing sport are the only two options is explored, and a number of other possibilities are outlined. The paper considers the picture that appears to have motivated the idea that there is a problem here in need of a solution. One alternative picture is offered by means of a discussion of the phenomenon of aspect-perception, which, it is argued, is not a helpful model for thinking about football (soccer) spectatorship. This alternative picture is not a rival theory, but one possible example designed to show that there are other ways of thinking about football spectatorship that dissolve the problem with which Mumford is concerned.

\section{Introduction}

Modifying a contrast found in Dixon (2001), Stephen Mumford (2012; 2012a) distinguishes between 'partisan' and 'purist' ways of watching sport. Recognising that the extreme partisan and extreme purist positions do not explain the nature of sports spectatorship, Mumford follows Dixon in adopting the idea of moderate partisanship (any spectator who is neither all-partisan nor all-purist). In thinking about the way Mumford employs the distinction between partisan and purist ways of viewing sport, one might question the plausibility of the idea of the purist way of watching sport (e.g. see McFee, 2014; 2015), or even raise questions about the coherence of the idea of a partisan in the context of, for example, watching footballi ${ }^{\mathrm{ii}}$. However, my concern here is more with the distinction as a whole and the problems that arise from viewing football spectatorship in the way Mumford 
suggests. In that sense, I have a somewhat similar concern to the one Austin (1962: 4) had when he pointed out that the expressions 'sense-data' and 'material things' 'live by taking in each other's washing'. The problem there, as Austin saw it, is that 'what is spurious is not [only] one term of the pair, but the antithesis itself'. So while it will, on occasion, be necessary to consider each of the two elements of Mumford's distinction, the principal focus will be on his overall conception, or way of seeing things, when thinking about sports spectatorship (although the focus here will solely be on football). As a consequence, particular attention will be paid to Mumford's suggestion that moderate partisanship consists in a capacity to oscillate between partisan and purist ways of watching football.

The paper begins by outlining Mumford's view of moderate partisanship as oscillation ( $\$ 1)$ before identifying the central features of the picture of football spectatorship he offers us (§2). Following a description of the method employed here (§3), some difficulties with Mumford's position will be identified and discussed in $\S 5$, via an investigation of one possible alternative conception of football spectatorship (introduced in $\S 4$ and elaborated in $\S 5)$. The paper will conclude (§6) with a brief discussion of the significance of the fact that what is offered here is not a rival theory, but one possible alternative conception (there are others) for the purpose of dissolving, rather than solving, what Mumford sees as the problem. ${ }^{\text {iii }}$

\section{Mumford on moderate partisanship as oscillation}

Stephen Mumford $(2012 ; 2012 a)$ not only argues that there are two kinds of sports fan, the partisan and the purist, but also that being a partisan and being a purist involves 'completely different ways of watching sport' (Mumford, 2012: 9). ${ }^{\text {iv }}$

The partisan supports one particular team (partisanship is rarer in individual sports). Mild partisanship involves identification with the team, following their progress, occasionally watching televised games, perhaps buying some merchandise, and wearing a team shirt 'with a degree of pride and self-identification' (Mumford, 2012: 9). Mumford conceives of partisanship as having degrees on a spectrum. Some partisans, those in the middle of the spectrum so to speak, will attend sporting events in person and participate fully in all the chanting and cheering that entails. Extreme partisans (who are to be found less frequently than the media would lead us to believe) will never miss a fixture, attending matches regardless of whether they are home or away. They are likely to collect memorabilia, and, to all intents and purposes, will appear to rarely think and talk about anything other than the object of their allegiance.

The purist has no particular allegiance, but has a deep love of the relevant sport. The purist may be concerned with the tactics employed by the competing teams, and have an appreciation of the relationship between tactics and different events and circumstances within the overall context of the game. The purist will appreciate skilful play, and have a different kind of appreciation of competition from the partisan. For example, the purist may appreciate instances of two players testing their skills and tactical abilities against each 
other, whereas the partisan would view such an event as largely indistinguishable from the battle of their team against the opposition.

While the partisan may be happy to see the opposition perform poorly, the purist would wish to see both teams perform to the best of their ability for the benefit of the match as a whole. The purist appreciates the fact that the result is not an essential component of what makes a 'good game'.

In response to arguments advocating some form of partisanship as the 'right' way to watch sport, Mumford (2012) defends the purist approach to watching sport, arguing in favour of a more aesthetic, rather than competitive, way of viewing the sporting event. ${ }^{v}$ This paper is not directly concerned with that debate, but rather with an addendum to Mumford's discussion of partisan and purist ways of watching sport. Mumford (2012a) addresses an issue neglected in his previous discussion of moderate partisanship (Mumford, 2012), namely, that the majority of sports fans will be neither entirely partisan, nor entirely purist. How are we to explain the ability of many sports fans to move between partisan and purist ways of seeing sport? And, what is 'the point of considering these pure aesthetic and pure competitive ways of seeing?' (Mumford, 2012a: 369).

Addressing these questions necessitates a rethinking, or perhaps an entirely different use, of the expression 'moderate partisan'. On the revised conception, the moderate partisan is no longer something of a partisan, but someone who doesn't care sufficiently about who wins the match to qualify as a more extreme partisan. Instead, the moderate partisan is someone who can move between watching sport from a competitive point of view, to watching sport from an aesthetic point of view. In that sense, the moderate partisan could have been called a 'moderate purist'.

This apparent ability to move between different ways watching sport draws attention to an important feature of Mumford's (2012; 2012a) account. For Mumford, different ways of seeing the sporting event result in the event that is seen being different. He (2012: 2-3) argues:

The expert sees a different game from the novice, and the aesthete sees a different game from the partisan. There may be a thought that these are mere clichés that should not be taken literally. For the expert, novice, aesthete and partisan may all be watching the same TV transmission and, one would think, it is obviously correct to say that they saw the same game. But ... watching means more than just having light hit one's retina, hearing means more than air vibrations moving one's ear drum, and so on. There is more to seeing than meets the eye .... Watching is something one does: the mind is active in it, ... there are thus different ways in which two people can look at the same thing. Two viewers with the same retinal image may not see the same. One taking an aesthetic attitude to sport may 'see a different game' to the committed fan, for instance, even though they observed the same event.vi 
There is a question of precisely how one is to understand the notion of the aesthete here. If someone were to watch football as a pure aesthete, then they wouldn't be watching football at all, but rather the movement of human bodies and the movement of a ball. This issue will be discussed further below (§5).

Mumford (2012a) is concerned with how one might explain this apparent ability to move between different ways of seeing a sporting event such as a football match. He considers three theories: the true perception theory, the mixture theory and the oscillation theory.

i. True perception theory: the moderate fan is able to see the event as it really is, rather than concentrating on an aspect (as the extreme purist and extreme partisan do). However, Mumford rejects the true perception theory, arguing that true, unmediated, perception isn't possible. He, rightly, points out that the true perception account can't explain the competitive and aesthetic focus because it claims the moderate partisan sees sport in an 'entirely different manner, unmediated by any desires and expectations' (Mumford, 2012a: 373). vii

ii. Mixture theory: the view that 'the moderate partisan has both partisan and purist perceptions of sport in some mixed way' (Mumford, 2012a: 373). This has the advantage of allowing any mix of partisan and purist ways of watching sport - so we don't just end up with three types of fan, the partisan, the purist and the moderate.

Mumford regards the mixture theory as preferable to the pure perception theory, but he doesn't think it is sufficient. Again, he would seem to be quite right in that judgement, as it hardly tells us anything to say that the moderate partisan has both partisan and purist perceptions of sport in some mixed way. That only seems an advance on the pure perception theory because it avoids the troubling view of perception found in that theory. So the advance isn't really one towards a better understanding, but rather avoidance of something troubling from a rival theory. Mumford (2012a: 373) stresses that:

We need also to know the mechanism by which degrees of partisanship and purism can be mixed in sports fans. If this mixture is of an irreducibly qualitative nature, then some mystery still remains. Indeed, it might suggest that there are continuummany different ways of watching sport, corresponding to all the different varieties of moderate, some with more partisanship than purism, and vice versa.

iii. Oscillation theory: the moderate sports fan switches or oscillates between competitive (partisan) and aesthetic (purist) ways of watching sport (see Mumford, 2012a: 373).

Mumford favours the oscillation theory, arguing that it has two advantages over the other two theories:

a. It doesn't posit a new, third way of watching sport. 'The moderate sees in both the competitive and aesthetic way, and no other, switching between them at different times' (Mumford, 2012a: 373 emphasis added). 
b. The oscillation theory permits qualitative analysis of spectatorship. 'The different possible mixtures of partisan and purist can be accounted for in a quantitative manner rather than as irreducibly qualitative. Simply put, the degree to which one is a purist, for instance, is fixed by the degree to which one perceives a game aesthetically. Switching back and forth between competitive and aesthetic perceptions of sport, one might find one fan tends to spend only $30 \%$ of their spectatorship aesthetically while another fan tends to spend $40 \%$ of their time. Our first fan is less of a purist than our second, therefore' (Mumford, 2012a: 373).

\section{Mumford's picture}

Before considering some troubling elements of Mumford's advocacy of the oscillation theory, it will first be helpful to draw attention to the picture that is in operation (consciously or otherwise) in his account. viii The picture is, in a certain sense, rather like someone playing two parts in a radio play where there are only two characters and sometimes very rapid dialogue between the two. A number of features can be identified:

i. There are two extremes (the purist and the partisan), and the majority of spectators watch sport in a way that can be thought of as on a spectrum running between these two extremes.

ii. There are only two elements to consider (the partisan and purist).

iii. There is a puzzle (for Mumford, a problem) about how the two elements are connected.

iv. There is a notion of proportions (quite literally measurable and related to time) of the two elements within any individual instance of spectatorship.

v. It is implied that at any given time a spectator can be assessed as viewing sport either in the partisan way or in the purist way (there are no other options, not even, at any specific time, a combination of the two).

vi. Spectators oscillate between the two options (partisan and purist ways of viewing sport) and over the period of the whole match (or a season etc.) the spectatorship of an individual can be thought of as combining the two elements and placing someone on a spectrum between the two extremes by means of a quantitative measurement.

vii. The two elements (partisan and purist ways of watching sport) are viewed as pure forms that exist in their entirety in given (sometimes short) periods of time.

Drawing attention to these features of the picture found in Mumford's account of sports spectatorship (and more specifically, of the spectatorship of the moderate partisan) provides some points of reference in considering the worries outlined below that one might have in relation to the account offered by Mumford. Before turning to those worries ( $\$ 5)$, however, I will outline the method to be employed here (§3) and then consider one possible alternative conception, while hinting at a few others (§4). 


\section{Some remarks on method}

Mumford's account is heavily influenced by a focus on perception. ${ }^{\mathrm{ix}}$ In looking for an alternative conception one might turn away from a focus on perception, but my concern here is not to offer an alternative account in opposition to Mumford's. On the contrary, I want to show that there are other possible conceptions that dissolve the difficulties that arise from Mumford's own conception. ${ }^{x}$ This can be achieved by showing that the worries outlined below arise from a particular conception that we need not be committed to, as there are other options. The range of possibilities open to us in trying to dissolve the worries is far greater than one might think and affords us a freedom in avoiding puzzlement that it is easy to fail to see. It is rather difficult to keep a clear view of the range of possibilities because of our tendency to be gripped by a particular way of viewing things - what I'm calling, following Baker (2004), a particular 'conception' or 'way of seeing things' that can be thought of as encapsulated in a picture. ${ }^{\mathrm{x}}$

Given my aim here, I will stay relatively close to the focus on perception that Mumford has introduced because that is necessary if I am to show that the problems one might find in Mumford's account of spectatorship arise from the picture that orientates his view of the topic, drawing certain features to the fore and pushing others to the background. One way of describing what I'm doing here is to say that I'm playing around with what is pulled to the fore and what is pushed to the background for the purpose of trying to show that doing so can dissolve many of the things someone might find puzzling about football spectatorship.

One way of thinking about the worries raised below in $\S 5$ is to see them as a consequence of the picture of football spectatorship outlined in $\S 2$. The idea here is that the reasoning goes something like this: 'If football spectatorship is like this ..., then this is like that ..., and this is like that ..., but that means that we face the following problem(s) ...'. Clearly, approaching things in that way is particularly vulnerable in relation to the initial conception contained in the picture of football spectatorship (the general way of seeing football spectatorship). Someone might point out that replacing one picture with another does not necessarily eliminate that vulnerability. It would only do so if the new picture was the right one. But, as Baker (2004: 262) stresses, a picture cannot be either true or false, it is simply a picture (see $P I \S \S 295$ and 424, ${ }^{\text {xii }}$ and Morris, 2004: 10), ${ }^{\text {xiii }}$ our concern should be with how it is applied $(P I \S \S 374,422-7)$. An alternative move here would, therefore, be to stress the possibility of other conceptions and to explore whether a greater awareness of the possibility of other conceptions allows us to dissolve (rather than solve) some of the problems raised by Mumford's approach. So the aim here is definitely not to offer one picture as a supposedly better alternative to Mumford's picture, but rather to show that there are other possibilities, and that those are not mere possibilities, but have the potential to dissolve our puzzlement if an appropriate picture is employed in a given context.

One concern someone might have here is that talk of alternative conceptions disregards any notion of the right picture, or getting the right account of football spectatorship. That very much depends on how we understand the word 'right' in that context. If, by 'right', 
someone means that football spectatorship is really some single, determinate, way, and the job of the philosopher is to work out what that is - in short, that the philosopher should construct a theory to tell us what football spectatorship really is - then it doesn't so much disregard that view, as take it to be misconceived. If, on the other hand, 'right' is understood as any picture that removes our puzzlement, then talk of alternative conceptions certainly does not disregard the notion of the right picture, but what is the 'right' picture will be a highly contextual matter and different pictures will help different people with whatever is puzzling them.

Why this reluctance to pursue an account of what football spectatorship 'really is'? If, when faced with the question 'what is it made of?' (asked of a wooden table), a carpenter tells us that it is made of oak, and a physicist tells us that it is made of quantum mechanical particles, and is mostly space, then the physicist hasn't told us what it is really made of any more than the carpenter has. Clearly, the expression 'made of' in this context refers to what it consists of (what kind of stuff it is), not to the materials someone used to make the table. No one makes things using quantum mechanical particles; they use wood, stone, bricks etc. The two replies are answers to the same question (in the sense of the same words) asked in different contexts (so, in another sense, they are two different questions entirely). The difference in this context lies in the concepts mobilized in the perceptions of the physicist and those of the carpenter. The physicist's answer is only helpful as a reply to the question asked in some very specific contexts, but in those contexts it is very helpful, and far more so than the answer the carpenter gave. Equally, the physicist's answer is of no use if the question is being asked by someone thinking of buying the table (and they want to know whether it is made of a good solid wood or some kind of cheap board with a veneer), or if someone needs to build a fire and they want to know how well the wood will burn. So the notion of an account of what football spectatorship really is seems overly simplistic, although to say this is not to say that we have no use for the notion of something being real (see Austin, 1962: 62-77). For example, if some context requires us to contrast a duck (the bird) with, say, a toy duck, or to contrast a Rembrandt with a forgery of a Rembrandt, then we have perfectly good uses for the notion of something being real.

Having clarified the method employed here, it is necessary to suggest an alternative way of seeing football spectatorship as an example to illustrate the fact that there are other possibilities. In $\S 4$ I will introduce an alternative conception before developing it by considering how it helps dissolve the difficulties one might find in Mumford's way of seeing football spectatorship. As already noted, this is simply an example of one possible alternative conception. The idea that there are others will be discussed briefly in $\S 6$.

\section{Alternative conceptions}

At the risk of appearing to slip into metaphysical jargon we might say that the event (the football match) is a complex whole. To say that, is, however, to do nothing more than to draw attention to (to bring to the fore) the fact that there are lots of things we might say about the event, including lots of things that might be perfectly appropriate descriptions in some contexts, but not in others, or that might be more or less helpful when faced with 
different concerns or puzzlement. Equally, the same is true of the descriptions we might give of football spectatorship.

In thinking about football spectatorship we are (at least) concerned with descriptions of the behaviour of spectators (including things they say), and descriptions of the event that they are watching, in both the sense of the match as a whole, and occurrences within the match. ${ }^{\text {iv }}$

Behaviour, events and occurrences each admit of multiple descriptions. ${ }^{x v}$ Also, it isn't obvious where a 'piece of behaviour' begins and ends, and what counts as part of the behaviour and what doesn't, and similar problems arise in relation to what I am calling occurrences within an event (often, but not necessarily, actions). One might also say that despite the fact that the match lasts ninety minutes, it's not obvious it's always helpful to think of the match and the event as the same thing when it comes to considering spectatorship. There's a lot that happens before the match, during half-time, immediately after the match, and, indeed, between matches, that might be of relevance depending on one's concerns. Equally, it's not always entirely clear what counts as the ninety minutes. For example, there can be disputes over what should and should not count as part of time added on for stoppages. Aside from those difficulties there seems to be no finite totality of inappropriate descriptions that one might give of behaviour, events and occurrences within events, nor does there seem to be a finite totality of appropriate descriptions. ${ }^{\text {xvi }}$ Also, appropriate descriptions are frequently non-additive (or at least needn't be additive) in that one can take two appropriate descriptions and find that it doesn't seem to be possible to add them together to get a more comprehensive description. ${ }^{x v i i}$ In that sense, different appropriate descriptions can appear contradictory, yet fixing the context of each description can show them to be appropriate 'pictures of one phenomenon' (Travis, 2011: 229). ${ }^{\text {xviii }}$

Behaviour, events and occurrences are complex wholes in the simple sense meant by that expression here (there's a lot one can say about them), and the descriptions we give of them draw attention to aspects. Aspects aren't parts. One way of seeing this distinction is to think of aspects as features of a whole rather than parts of a whole. So Constable's brushwork is an aspect of his painting, or of a particular painting, but the bit that shows Willy Lott's cottage is a part of The Hay Wain. It would be possible (although hopefully it will never happen) for someone to cut Willy Lott's cottage out of the painting and lay it on the table in front of us, but no one could do that with Constable's brushwork. The closest they could come to that is to present us with examples of his brushwork in individual paintings, drawing our attention to that aspect of the work.

Descriptions of behaviour and action, and of events and occurrences, also seem to be occasion-sensitive (see Travis, 2008) in that the context of a description affects both what is said and whether it is true. In addition to the fact that behaviour, action, events and occurrences admit of multiple descriptions, there is also an issue around who is doing the describing. If the relevant descriptions here are subject to interpretation and are occasionsensitive (context, culture, language and the conceptual framework are all relevant), then 
there seems a need to consider that in relation to both the giving and the hearing of descriptions.

In recognising that behaviour, action, events and occurrences admit of multiple descriptions, and recognising the occasion-sensitive nature of such descriptions, a number of features of the conception described here can be brought together. David Best (1974: 39) illustrates the notions of multiple description, occasion-sensitivity (of questions, answers and descriptions), the mobilization of different concepts in the perceptions of different interested parties (such as those described in the examples of the physicist and the carpenter above), the grip of a particular picture of 'real', and the idea of aspects of a complex whole in his description of a cricketer hitting a six:

The expectations of the questioner often determine, at least to some extent, the answer. A Cricketer hits a six and the question is asked, "What did he really do?" Despite the implication in the question, there are various possible answers, for example, in terms of physics, psychology, and physiology. Or we could reply, "He won the match," "He lost the ball," "He broke his bat," "He demoralised the bowler," "He broke the pavilion clock," "He split his trousers," and so on. We usually know how to answer because we know the sort of answer expected, and this can sometimes mislead us into thinking that there is a single correct answer.

There is no single correct answer, but that is not simply a consequence of the fact that different concerns (different contexts for the question) require different answers. There would still be various answers that might be perfectly acceptable because of the variety of ways that something might be described. So it's important to recognise that it is not simply that behaviour, action, events and occurrences admit of multiple descriptions that is important here, but that they admit of multiple appropriate descriptions even when we have done everything we could possibly do to fix the context of the question or of someone's concern in asking for a description. As a consequence, disambiguation will not eliminate occasion-sensitivity, and there can be no finite totality of possible appropriate descriptions (see McFee, 2004: 49-52).

So the ability to give different appropriate descriptions (as in the case of the physicist and the carpenter) can be seen as a consequence of our ability to draw certain aspects of a complex whole to the fore while pushing others to the background, and that is also why Best's description of the cricketer hitting a six contains so many possibilities that could easily be mutually compatible or appear to be incompatible while remaining perfectly appropriate descriptions of the incident because some descriptions bring certain aspects to the fore and push others to the background, while other descriptions draw different aspects to the fore and suppress others.

This section has suggested a shift in focus by thinking of football spectatorship as a complex whole that admits of many appropriate descriptions. By placing an emphasis on the notion of aspects it is possible to draw certain aspects to the fore and push others into the 
background in exploring possible descriptions for the purpose of dissolving any particular confusion someone might have in a specific context. In $\S 5$ I illustrate this in relation to some difficulties one might find in Mumford's account of spectatorship.

\section{Creating disquiet and suggesting alternative possibilities}

The remarks in $\S 4$ sketch some options in looking for alternative conceptions of football spectatorship, but they require further development. In $\$ 5$ I will explore one possibility (not to be understood as a mere possibility) and develop it further by considering some worries one might have about elements of Mumford's account and the associated picture.

In relating those worries to the elements of the picture in operation in Mumford's account I aim not only to develop a clearer view of one possible alternative conception, but also to show how alternative conceptions can dissolve those worries.

\section{i. The idea of a spectrum}

The use of the notion of a spectrum is not necessarily incomprehensible, but it is certainly a lot more baffling than it at first appears. The danger is that it lends an apparent clarity that on closer inspection appears to actually be rather unclear.

Equally, to invoke the notion of a spectrum to describe football spectatorship, raises the question of how we are to think of either end of the spectrum, and the problem of what we are to say of things off the spectrum. In the case of spectatorship an initial concern must surely be whether either end of the spectrum is plausible as a way for anyone to be, or whether they are just ideal types used as heuristic devices. Mumford (2012a: 371) suggests that partisan and purist may be 'ideal limits on a spectrum while all real spectators are somewhere in between'. This leads to a concern with whether the two options offered (partisan and purist) are the only possibilities. If there are other options, then there are things of relevance not captured by the spectrum (things off the spectrum), and problems start to arise around how we account for those things off the spectrum and any boundary between them and the ends of the spectrum. Invoking the notion of a spectrum avoids the need to give a clear account of boundaries on the spectrum, but not between those things on the spectrum and those off the spectrum. If everything is on the spectrum, then it is hard to see how the notion of a spectrum explains anything.

So one concern is whether the metaphor of a spectrum (element i of Mumford's picture) actually explains anything, and there is also a question about how we are to visualise the spectrum and what we are to make of those things that are off the spectrum and at either end of the spectrum. These difficulties arise from the idea that there are two extremes (element ii of the picture) that form the only reference points in Mumford's account of spectatorship. This idea emerges in the first feature of the picture in operation in his account, but recurs in many of the other elements of the picture. In relation to element vii of Mumford's picture, seeing spectatorship as a complex whole of which we can give many, non-additive, appropriate, descriptions, the usefulness of which is influenced by the context 
of the description and the concern or confusion that is being addressed, avoids the difficulties raised by being locked into an account in terms of only two elements.

\section{ii. Are there other foci? ${ }^{x i x}$}

In considering the issue of whether there are other foci for those watching, say, a football match, Mumford lists watching sport disinterestedly, watching sport for gambling purposes, and watching sport as a statistician. We might want to say, however, that disinterested watching is really just 'looking at' the event, and therefore not watching it in the relevant sense. Equally, gambling doesn't really change the watching - it's still about who wins (as in competition). The statistician's view isn't really about watching at all, it's about results and facts about the game, which don't actually require you to watch the game itself. Having questioned whether the candidates for other foci that Mumford offers (and rejects) are cases of watching sport in the relevant sense, it is possible to go further and question whether someone who sees football purely in an aesthetic way can be properly thought of as watching football, given that watching that way is to show no interest in central features of football, which is, after all, a purposive sport. The movements of human beings that take place in a football match may be seen as beautiful, although surely some will not be, but they are not seen as actions in football if they are not seen as part of a sport where those actions are understood in terms of winning and losing.

But there are surely other possibilities here. Might we consider, inter alia, a focus on the following?

a. the spectacle;

b. the drama or tension;

c. a sense of community (as might be found in non-league football);

d. a sense of culture;

e. a sense of identity.

Drama might be thought to count as aesthetic, but that is to fail to recognise that to call a football match or elements of that match 'dramatic' is not the same use of 'dramatic' as we find in discussion of a play. Best (1978: 117-19) stresses that the common uses of 'dramatic' and 'tragic' (in relation to plays) are employed in contexts where things happen to characters, not to the actors playing the parts. The absence of any 'comparable convention' (1978: 118) in sport means that drama in sport is not drama of the aesthetic kind. The same conclusion can be reached by a different argument. Plays are creative endeavours; the aesthetic and the artistic nature of plays stems from the fact that they are written, acted, directed, staged (lighting, costumes etc.), and that all of those are creative endeavours. By contrast, it is extremely important that sporting events are not scripted and the outcomes are not determined in advance. ${ }^{x x}$ So we should not mistake the metaphorical use of 'dramatic' in the context of description of a football match for the standard use of the term 
in relation to plays; the latter does imply artistic and aesthetic qualities, but the former does not.

Someone might wonder whether focussing on a sense of culture or on a sense of identity entails some degree of identification with teams, even if that is only on a temporary basis. ${ }^{x \times i}$ That may be the case, but such identification would fall far short of allegiance, and even if identification of the relevant kind brought a degree of partisanship, it is a very different kind of partisanship from that based on allegiance. We might even regard it as something other than partisanship in that to be partisan could be thought of as requiring more than wanting one team to win, but to also have an allegiance to the team one wants to win. That is not a position that need be advanced here; the point is that what wanting a team to win would consist in would be quite different in the case of someone whose spectatorship was focussed on a sense of culture or a sense of identity when compared to Mumford's partisan.

So there seems no reason to think that partisan and purist ways of watching sport are the only options; it isn't like night and day, where more of one means less of the other.

Thinking of spectatorship in terms of aspects allows us to recognise the variety of things that may function as foci for someone's appreciation of a football match. Recognising that variety further reduces the need for the metaphor of a spectrum (feature i of Mumford's picture), takes us away from the idea that there are only two foci to consider (features ii and $\checkmark$ of Mumford's picture), and dissolves the apparent problem of how the two elements are connected because they are never regarded as disconnected in the first place. Aspects are, by their very nature as aspects, elements of something that has other aspects. To ask how two or more aspects of a whole are connected is to fail to understand the nature of aspects. They are not parts, and it makes no sense to ask how they are connected to each other in the way that it does to ask that question about parts of an object. Similarly, any concern with proportions (feature iv of Mumford's picture), and certainly any notion of quantifying proportions in relation to aspects, makes no sense and would be to misunderstand the nature of aspects.

\section{iii. The use of 'aesthetic'}

Mumford tends to treat the purist as someone concerned with aesthetic matters. For example, he (Mumford, 2012: 7) says that '[p]urists are distinguished from partisans, where the former watch sport for more aesthetic and intellectual reasons while the motivation of the partisan is more emotional and victory-seeking.' The aesthetic and the intellectual are not the same thing, and while he mentions both aesthetic and intellectual reasons, his emphasis seems to be heavily on the aesthetic rather than the intellectual.

However, he seems to want to include time as in some way an aesthetic matter (Mumford, 2012: 24), yet it seems strange to think of time as an aesthetic concept, even if time affects the conditions for aesthetic criteria. The two-and-a-half-minute recording and Wagner's Der Ring des Nibelungen (which lasts fifteen-and-a-quarter hours in total and is performed over three days and a preliminary evening) have different temporal properties, but it seems odd 
to think of those properties as aesthetic properties. It seems less troubling to think of them as conditions for different aesthetic possibilities. If a composer has hours in which to allow a piece of music to develop, as opposed to having to confine the finished work to two-and-ahalf minutes, then the range of aesthetic possibilities available to that composer is quite different from those available to the person composing a short piece of music. ${ }^{\text {xii }}$ Indeed, the component operas of the cycle (Das Rheingold, Die Walküre, Siegfried and Götterdämmerung) and the acts within those are partly as they are precisely because they are part of a larger work.

The concern in relation to Mumford's use of 'aesthetic' is that sometimes things that it doesn't seem natural to treat as aesthetic concepts (the example here was time, but he does the same with notions such as drama and excitement, see Mumford, 2012: 19 and 4956) seem to be treated that way in order to make them fit the account of the purist, which is essentially someone who watches sport with aesthetic and intellectual concerns. ${ }^{x \text { xiii }}$ Seeing spectatorship in terms of aspects (contrary to element vii of Mumford's picture) avoids this problem because there are so many additional foci beyond the concern for the aesthetic and the intellectual on the one hand, and the purposive or competitive on the other. ${ }^{\text {xiv }}$

\section{iv. Quantification and aspect-perception}

Why is a quantitative account to be thought of as superior? Mumford (2012a: 373) seems to suggest that there is something troubling about the idea that the mixture between degrees of partisanship and purism in spectatorship is irreducibly qualitative because 'it might suggest that there are continuum-many different ways of watching sport, corresponding to all the different varieties of moderate, some with more partisanship than purism, and vice versa'. Someone might reasonably question why that should be thought of as a problem. The idea that it is a problem seems a consequence of Mumford's picture. Commitment to two foci (elements $i$ and ii of Mumford's picture) renders the threat of continuum-many different ways of watching sport a serious problem because if there are continuum-many ways of watching sport, then a fortiori there aren't only two foci of importance in any viable account of spectatorship. Mumford's concern with proportions and quantification seems to follow from his commitment to two foci and the need to avoid the conclusion that there are continuum-many ways of watching sport because such a conclusion would require abandonment of the commitment to two foci, and therefore to the overall picture that is in operation in Mumford's account. If there aren't only two possible foci, then there isn't necessarily a puzzle about how foci are connected, and certainly not only about how the partisan and purist foci are connected. Also, once the commitment to two foci is abandoned, then the question that the notion of oscillation is employed to answer doesn't arise, or at least the question wouldn't be about the connection between the partisan and purist ways of watching sport, but about the connection between a number of possible foci (although thinking of spectatorship in terms of aspects avoids that problem arising).

Equally, someone might question whether the precision that would be necessary to distinguish the quantitative from the qualitative in relation to spectatorship, such that any 
meaningful measurement could be made, is possible. One thought, popular in some forms of psychological research, is that measuring eye tracking can tell us where someone's attention is focussed. However, that only gives an indication of where someone's gaze is trained. ${ }^{\mathrm{xxv}}$ It doesn't tell us whether they are really paying any attention to the thing on which their eyes seem focussed. Some people look away in order to concentrate more fully on something, so tracking their eye movements under the assumption that their eyes will fall on that to which they are paying attention can be very misleading. Also, spectatorship is such that there aren't discrete objects associated with the purposive and the aesthetic. The purist and the partisan would be looking at the same thing as far as eye tracking is concerned. Our concern here is not with where someone's eyes are directed, but with what they notice and appreciate. To get an indication of that it would be necessary to consider their behaviour, including the things they say.

Another concern one might have in relation to our ability to distinguish the qualitative from the quantitative in relation to spectatorship is highlighted by a group of questions someone might reasonably ask: what timeframe would be a reasonable period in which to measure whether one person was more of a purist than someone else? If Smith is more of a purist today, is that it, or should we consider next week, or the week after? If we can fix a period of time that is of relevance, then how do we know that Smith's partisanship or purism isn't more intense than that of Jones? It isn't obvious that one can guarantee a single dimension here.

So the concern remains: can the two ways of watching sport really always be separated at any given time in the way Mumford (2012a: 373) suggests? ${ }^{x x v i}$ As descriptions of behaviour there seems no reason to think so. ${ }^{x x v i i}$ For example, imagine someone who appreciates the beauty of a particular series of passes, or of a free kick that curves the ball round the wall to score in the top corner of the goal. We might say that someone has appreciated the beauty of such things if their team is on the receiving end of the skilful act, but what could we say if it is their team that displays those skills? Might we not then have difficulty distinguishing between partisanship and purism? Might not the appreciation of the beauty of the case at hand be heightened by the fact that a competitive advantage has been gained? While it might be a perfectly good description in many circumstances to say that the spectator has displayed a purist appreciation of the display of skill, it would surely be the circumstances under which we were giving a description of the spectator's behaviour that would dictate whether that really was an appropriate description, or whether it might be better to give a description that drew attention to a heightening of the appreciation because of the competitive advantage gained, or even a description that took the spectator to be solely motivated by partisanship, despite the beauty of the case under consideration. ${ }^{x v i i i}$

Clearly there are differences between thinking of football spectatorship in terms of watching a whole match, and thinking about watching different occurrences within a match, it is useful here to look at an example of an occurrence within a match. Consider the various ways that one could appreciate the Cruyff turn. 
For example, one could appreciate it as beautiful, as clever, as creative, as ingenious (something of a combination of clever and creative), as cheeky (rather like the antics of Steve Ovett or Muhammad Ali), as brave, as good football, as unique, as historic, as iconic, as novel, as gaining a competitive advantage, as displaying superiority over (or even as humiliating) the opposition, as a technique that someone could learn or teach (now that it is established), and, no doubt, in other ways (cf. Best's (1974: 39) description of someone hitting a six in a cricket match discussed above).

Appreciating the Cruyff turn in one of those ways is not a denial of other possible ways of appreciating it (or, at least, it need not be). A more helpful way of thinking about the different ways of appreciating it is to think of them as pulling one aspect to the fore, and pushing others to the background. Of course, often pushing aspects to the background can lead to us becoming blind to them altogether. Or, to put it another way, pulling a certain aspect to the fore can lead to us being gripped by a particular picture to the point that we seem incapable, or at least have great difficulty, in seeing things other ways. ${ }^{x x i x}$ This often leads to the view that things must be a particular way, and something like the form of reasoning described above - 'If football spectatorship is [must be] like this ..., then this is [must be] like that ..., and this is [must be] like that ..., but that means that we [must] face the following problem(s) ...'.

The example of the Cruyff turn helps show that there are very many possible foci for our appreciation of such an occurrence, and that many of them seem to have nothing to do with partisanship or purism.

Distinctions are usually made for a purpose in a context. In some contexts the distinction between partisan and purist ways of watching sport will help us understand some example of spectatorship, but in many other contexts some other contrast will be needed because it will be more helpful. Also, in some contexts the distinction between partisan and purist ways of watching sport will be misleading and contribute to confusion. Strictly speaking, talk of 'contexts' here isn't quite sufficient. The same person on two different occasions may find different contrasts helpful in avoiding confusion. There's no right or wrong tool in such circumstances independently of what does the job of alleviating confusion or puzzlement on the occasion at hand (and not necessarily elsewhere).

Presumably the thought that quantification is possible stems from the idea that when we see the Neckar cube or the duck-rabbit one way, we can't, at the same time, see it the other way. But the Neckar cube and the duck-rabbit are specifically designed to have that property. Complex wholes like a football match, however, are quite different. The match is continually changing and contains discernible occurrences that can be considered in isolation (the Cruyff turn, a free-kick, a penalty, a particular tackle or clearance, a specific pass, even someone's running off the ball etc.). When we see the Neckar cube or the duckrabbit a particular way, it is usually because that is the way it strikes us, not because we approached it with a particular way of seeing it in mind - the duck way of looking at the duck-rabbit for example, say, primed by looking at lots of pictures of ducks first (PI p. 167). 
Yet the partisan and purist ways of watching sport sound much more like the kind of ways of seeing that one can cultivate and then approach the event already motivated to see it in that way. So the analogy of the Neckar cube or the duck-rabbit seems misleading here.

Not all perception is aspect-perception (not all seeing is seeing-as), and not all use of the notion of an aspect is the same as the use of that idea in aspect-perception. ${ }^{x x x}$ Failing to appreciate that can lead to aspect-perception being taken as a model for spectatorship when it really doesn't lend itself to that use. Recognising that removes the original motivation for thinking in terms of quantification here (the idea that in seeing one way, one can't, simultaneously, see in another way). That doesn't mean that one can't look to quantify the different kinds of spectatorship, but that one needn't; there seems no particular reason to do so.

So one possibility here might be that having considered the various ways in which aspectperception is not a helpful model for spectatorship, along with the various remarks about other elements of the picture in operation in Mumford's account, someone initially sympathetic to the idea that quantification would be desirable in considering spectatorship might leave that particular idea of their own accord (LFM p. 103). ${ }^{\mathrm{xxxi}}$

Clearly, this is of direct relevance in relation to elements iv and $v$ of Mumford's picture, but it is also important in relation to element vi because if we give up the desire to clearly isolate ways of seeing a football match as if they were quite distinct from each other, then the notion of oscillation starts to look fragile in the sense that the need for it disappears. If we can watch the match and discern aspects of what we see (and sometimes also hear etc.), which enable us to say many different things about what we have seen (both immediately and later), ${ }^{\text {xxii }}$ then the concern with the things we might appropriately say (as opposed to things that seem just plain wrong) doesn't seem to be addressed by the notion of oscillation, but rather by paying attention to the context in which one might be giving a description or be making a point, and the concern one might have at that time.

\section{v. The nature of the football match}

Mumford (2012a: 373) describes the oscillation he attributes to spectators as follows: 'The idea would be that our moderates are able to switch between the two available ways of seeing with varying rapidity ${ }^{x x i i i}$ during a game that they watch. At times they get excited when a goal is nearly scored but at other times they get lost in the aesthetics of a particular play or admiration of the athletic form'.

This treats the game as always the same thing; as if watching the game is like looking at a painting. The game/event is not like most (although not all) cases of painting insofar as it changes and isn't always aesthetically appealing, and it isn't generally designed to be so (artistic interest doesn't necessarily require beauty etc.). The idea that rapid switching takes place contains within it the idea that the game is the same and the way the spectator views it changes (for reasons that are not clear). But the game is changing all the time, so both the way the spectator watches, and the game being watched, are continually changing during 
the course of the event. What the spectator is watching at any given time is distinct; the fact that we refer to the whole ninety minutes of play as 'the game' does not mean that for the purpose of trying to make sense of someone watching the game, we can treat it as a fixed entity, the contemplation of which is like that found when looking at a painting.

This is another area in which the idea of there being only two options (elements $i$ and ii of Mumford's picture), the model of aspect-perception (a motivation for elements iv and v), and the notion of oscillation (element vi) all start to look less compelling. A football match and a diagram such as the Neckar cube or the duck-rabbit just don't resemble each other sufficiently for the notion of aspect-perception to be helpful. Not only is it the case that there are many different things one might focus on in watching a football match, not just two, but the match itself is continually changing (unlike the diagrams). It isn't even clear that there is only one thing that we might take as the 'object' (the thing being watched) in the case of a football match. As already noted, we might think of the match as everything that happens between the points at which the referee blows a whistle, or perhaps everything between those points and what goes on at half-time, or we might include some of what happens before and/or after the match, or we might narrow our focus and consider specific things that happen during the match, which are often, but not always, actions and can be viewed as distinguishable from the rest of the match.

Thinking of spectatorship in terms of two ways of seeing, and then looking for an account of how those ways of seeing are connected doesn't seem to be to operate with a suitably complex and subtle view of the nature of a football match as something that is spread over time, changes over time, can be described in many appropriate, and often non-additive, different ways depending on one's concern in giving a description, can be seen as containing occurrences that we frequently wish to distinguish from the match as a whole, and which is subject to some debate (perhaps settled by reference to the context of one's concern on a given occasion) as to what counts as part of the match and what does not. That seems a very long way from a diagram designed to be seen in two ways on different occasions, even if, with some imagination, it can be seen other ways.

\section{vi. Aspect-perception as a model}

Mumford takes aspect-perception as a model for his account of watching sport, but someone might reasonably question the appropriateness and usefulness of aspectperception as a model for football spectatorship. Indeed, we might question whether these are really ways of seeing at all. Isn't visual perception the wrong picture/model here? Are they ways of engaging, or ways of valuing? They don't seem to be like the duck or the rabbit in the duck-rabbit. The aesthetic view might be a way of seeing, but it's not clear that the focus on competition (or any of the others raised by Mumford, or by me here) are. And the aesthetic view isn't a 'way of seeing' in the sense of 'seeing-as', such as is found in the duckrabbit or the Neckar cube. 
The categories of partisan and purist are broad classifications. In one sense, it is not that someone sees the football match, or some part of it, as partisan or purist, but as a partisan or as a purist. In other words, it is the things that they do and say as spectators that lead us to want to call their view of the match, or part of the match, either a partisan or a purist view. The way someone sees the match is influenced by how they engage with that event. This doesn't seem to be the same as seeing the duck-rabbit as a duck. When two spectators see an example of the Cruyff turn, it is the same as the case of the duck-rabbit in that the thing that they see is the same, but the way they see it is different (they describe it in different, and contradictory, ways). However, when someone sees the duck-rabbit as a duck, and someone else sees it as a rabbit, they see the drawing on the page as two completely different things. But when one football supporter sees the Cruyff turn as beautiful, and another sees it as an example of showing off that disadvantages his or her team, then the two football supporters still see the Cruyff turn as what it is, namely, an example of the Cruyff turn. The difference in the way they see the turn is not so much a difference in what they see it as, but a difference in what they see as the significance of it. If the partisan denies that some event could be seen in another way, then that denial is not a direct consequence of an act of perception. Likewise, if someone can only see the duckrabbit as a duck, and they deny that it can be seen as a rabbit, then that denial doesn't follow from the fact that they can only see it as a duck. The fact that I can only see it as a duck is not a sufficient reason for me to conclude that when other people say they can see it as a rabbit they are mistaken or lying.

If one is gripped by Mumford's picture of spectatorship (in this case particularly element v), then one is likely to find it much harder to see the difference in the uses of 'see' in Mumford's account. Breaking free of the influence of that picture while not being gripped by another, but employing it for the purpose of helping with some specific confusion, makes it much easier to notice the conflation of uses of 'see' that treats aspect-perception as a model for watching sport, where the aesthetic view isn't a 'way of seeing' in the sense of 'seeing-as', and often what is taken to be a way of seeing would be more accurately thought of as a way of engaging.

\section{Concluding remarks}

The aim here has not been to offer a rival theory to that suggested by Mumford. Indeed, no theory has been offered here at all (and deliberately so). Alternatively, I have made suggestions of other ways of thinking about (alternative conceptions of) football spectatorship for the purpose of showing that the problem Mumford is concerned with, and problems one might see as a result of his account, are a consequence of the conception with which he operates, and can be dissolved, rather than solved, if we appreciate the range of possibilities available to us in that regard.

It is important to stress that there may be other possibilities, not only the one explored here. However, that is not to argue that just any account will do (no doubt most won't). To 
recognise that there might be other possibilities is simply to stress that being gripped by an alternative conception is likely to lead one into confusion at some point. Other possibilities (and the one offered here) should not be understood as once-and-for-all exceptionless accounts. Other possibilities are not possible exceptionless accounts, but rather other possible ways of dissolving someone's confusion. Talk of other possibilities should not be misunderstood as a claim that nothing can be wrong, or that all accounts are as good as each other. First, any 'account' is likely to be problematic to the extent that it is thought to be exceptionless, but also there has to be scope for a claim just being wrong. For example, if Mumford thinks there are only two foci that are of importance to our attempts to understand spectatorship, and someone offers others (as I have here), and those are indeed relevant and important foci, then Mumford's claim that we need only consider two foci is wrong. However, that need not mean that it is not the case that sometimes, in certain contexts, focussing on the two foci Mumford suggests could help someone with something that is puzzling them about spectatorship. If treated as a theory or account designed to enable us to understand spectatorship in some exceptionless or even very general way, then it is likely to lead to confusion and some of the central claims will, in their generality, be wrong.

I have stressed the picture of a football match as a complex whole, which can have many foci for our appreciation at various times, and at any given time. I have also emphasised the wide variety of ways we can describe the event and occurrences within it, and stressed the importance of context, or our interest, in determining the appropriateness of descriptions in specific cases. Those features have been linked here in one picture and accompanying conception, but each could have been developed differently and perhaps independently of the others. Equally, someone might find it helpful in relation to what puzzles them (about Mumford's view or their own thought on football spectatorship) to think of the event in terms of dialectical reason, or, alternatively, they might find that thinking about allegiance as giving a motivation for spectators, and appreciation as also providing some kind of motivation, is helpful. This could be developed by thinking of the issue in terms of reasons, which might help with things that are troubling in Mumford's account without producing a rival theory.

So there are other possibilities, and what has been explored here is just one of those possibilities, which was principally considered as an example to show the potential benefits of looking for alternative conceptions to help dissolve puzzlement, rather than constructing rival theories to solve apparent problems. One way of thinking about what gets explained when that approach is taken is that it is how we came to think that we had a problem in need of a solution, but the outcome is that the problem disappears. 


\section{References}

Austin, J. L. (1962) Sense and Sensibilia, Oxford: Oxford University Press.

Austin, J. L. (1962a) How to Do Things With Words, Oxford: Oxford University Press.

Baker, G. P. (2004) Wittgenstein's Method, Neglected Aspects, ed. K. Morris. Oxford: Blackwell.

Best, D. (1974) Expression in Movement and the Arts, London: Lepus Books.

Best, D. (1978) Philosophy and Human Movement, London: George Allen \& Unwin.

Dixon, N. (2001) 'The Ethics of Supporting Sports Teams', Journal of Applied Philosophy, 18, 2: $149-58$

Frege, G. (1977 [1918]) 'Thoughts' In Frege, G. (1977) Logical Investigations, trans. P. T. Geach and R. H. Stoothoff, Oxford: Basil Blackwell, pp. 1-30.

McFee, G. (1999) 'Wittgenstein on Art and Aspects', Philosophical Investigations, 22: 3: 26284.

McFee, G. (2004) Sport, Rules and Values: Philosophical Investigations into the Nature of Sport, London: Routledge.

McFee, G. (2014) 'Making Sense of the Philosophy of Sport', Sport, Ethics and Philosophy, 7 (4): 412-29.

McFee, G. (2015) 'A Not-So-Beautiful Game', Sport, Ethics and Philosophy,

Morris, K. J. (2004) 'Introduction' In Baker, G. P. (2004) Wittgenstein's Method, Neglected Aspects, ed. K. Morris. Oxford: Blackwell, pp. 1-18.

Morris, K. J. (2007) 'Wittgenstein's Method: Ridding People of Philosophical Prejudices' In Kahane, G., Kanterian, E. and Kuusela, O. (eds.) (2007) Wittgenstein and His Interpreters, Oxford: Blackwell, pp. 66-87.

Mumford, S. (2012) Watching Sport: Aesthetics, Ethics and Emotion, London: Routledge. Mumford, S. (2012a) 'Moderate Partisanship as Oscillation', Sport, Ethics and Philosophy, 6 (3): 369-75.

Travis, C. (2008) Occasion-Sensitivity: Selected Essays, Oxford: Oxford University Press.

Travis, C. (2011) Objectivity and the Parochial, Oxford: Oxford University Press.

Travis, C. (2011a) 'Truth and Merit' in Gustafsson, M. and Sørli, R. (2011) The Philosophy of J. L. Austin, Oxford: Oxford University Press, pp. 175-203.

Travis, C. (2013) Perception: Essays After Frege, Oxford: Oxford University Press.

Wittgenstein, L. (1989) Wittgenstein's Lectures on the Foundations of Mathematics, Cambridge 1939, edited by C. Diamond. Chicago: The University of Chicago Press. 
Wittgenstein, L. (2001) Philosophical Investigations, third edition, trans. G. E. M. Anscombe, Oxford: Blackwell.

\begin{abstract}
i An early version of this paper was read to the International Council of Sports Science and Physical Education conference in Glasgow in July 2012. I am grateful to Stephen Mumford for the invitation to be a member of that panel. As always, I'm very grateful to Graham McFee for discussing some of the material in this paper, his subsequent detailed comments on a draft, and for allowing me to read 'Making Sense of the Philosophy of Sport' and 'A Not-So-Beautiful Game' while they were in draft form. Finally, I'm grateful to Steffen Borge for the invitation to contribute to this project, and the anonymous reviewers, whose comments were so interesting that limitations on space meant that I had to make the difficult decision not to explore here many of the points they raised, and none of them in the detail I would have liked.
\end{abstract}

ii All reference to 'football' is to Association Football.

iii Failure to grasp the fact that there is no theory offered here, not even some form of pluralism, will make it impossible to follow the argument. What is explored here is a context-sensitive method for dissolving philosophical puzzlement, not a theory providing an explanation of football spectatorship or a solution to a problem, such as the relationship between partisan and purist ways of watching sport. The suggestion (which has been made) that I should be bolder and present the material here as containing a rival theory, entirely misunderstands the argument (and what boldness consists in here), and is to fall victim to a preference for a particular form of explanation. The fact that one is comfortable with a form of explanation is no reason to favour it. Explanations have to be judged by reference to the things they purport to explain, not by whether we find their form appealing. However, this paper doesn't engage in the explanatory project at all. The explanatory project is rejected, not just Mumford's specific explanation. The argument here is as much concerned with the nature of philosophy as it is with football spectatorship - perhaps more so.

iv Referring to 'the purist' and 'the partisan' as if there were such pure types can be confusing. Mumford certainly uses these expressions (he frequently refers to himself as 'a purist'), but I've always understood this as a convenient, if potentially misleading, façon de parler.

$v$ It is important to stress that Mumford is not advocating what might be called 'pure purism', but rather a greater emphasis on the aesthetic appreciation of sport than is generally regarded as appropriate.

vi Compare Frege's (1977 [1918]: 26-7) claim that '[h]aving visual impressions is certainly necessary for seeing things, but not sufficient. What must still be added is not anything sensible. And yet this is just what opens up the external world for us; for without this non-sensible something everyone would remain shut up in his inner world'. Travis (2013: 387) also stresses, in commenting on Der Gedanke, that '[p]erception is a form of acquaintance with things which can be represented as being thus and so; .... But to take something to be a case of such-and-such, one also needs acquaintance with that such-and-such - for that way to represent things being, familiarity with its way of reaching to the particular case. Such, Frege points out, is familiarity with something not an object of sensory awareness, not liable to be before the eyes, or in the environment at all'. vii Given Mumford's criticism of true perception theory it might seem a little confusing that he also contrasts the 'impartial perception' of the purist with that of the partisan, claiming that such impartial perception is 'far more trustworthy than that of a partisan' (Mumford, 2012: 13) in relation to refereeing decisions and contested incidents. However, this is probably best not seen as a contradiction because 'impartial perception' could be understood simply as indicating an ability to see the events of the match free from the particular form of blindness to reasonable ways of seeing incidents on the pitch that can be a feature of the partisan way of watching sport. If so, then the claim that 'pure perception' is possible would be a stronger claim, and one that Mumford can deny while invoking the idea of impartial perception without contradiction.

viii Someone might wonder whether Mumford would accept the characterisation of the features of his account identified here. However, that would be to miss the fact that while many of the features are explicitly stated in his work, some, presumably those someone might think he may not recognise, are corollaries of those features that are explicit (it is in that sense, and only in that sense, that they may be unconscious). So Mumford's recognition of each and every feature is not as essential as one might think. What matters much more is whether any given feature is either explicit in his work, or follows from those features that are explicit.

ix He (Mumford, 2012: 7) stresses that, ' $[$ d] ifferent people can see the same sporting event in different ways. A purist and a partisan, for instance, or even two opposed partisans, can look at the same game but see it differently. This is more than a matter of simply holding different beliefs about what one sees. Perception is something that occurs with the mediation of thought, not separate from it. The idea that there is a distinctive 
aesthetic way of seeing for instance, is defended, whereas the partisan will have what we can call a competitive way of seeing the same sporting event.'

$x$ Another, more general, way of describing the aim here is to say that it is to dissolve Mumford's problem (the problem of the relationship between partisan and purist ways of seeing), rather than to oppose his solution to that problem. The dissolution of the difficulties that arise from Mumford's conception is really just a consequence of the dissolution of his problem.

xi Baker (2004: 260) finds this use of the notion of a conception in Wittgenstein, and notes that Wittgenstein 'often uses "picture" to characterize ideas which seem non-pictorial or even unpicturable'.

xii I employ the standard abbreviations for Wittgenstein's texts. In this case those are PI (Philosophical Investigations) and LFM (Lectures on the Foundations of Mathematics).

xiii There is a danger here of helping ourselves to the concepts of truth and falsity rather too easily. See Austin's (1962a: 143) discussion of the claim that 'France is hexagonal', where he stresses that '[i]t is a rough description, it is not a true or false one'. A picture isn't the same as a description, but pictures and rough descriptions are used in such a way as to not be amenable to consideration as true or false.

xiv Although we might go further and consider a season or a life as a spectator, such extensions might be thought to take care of themselves. Whether or not such things are important depends on one's concerns in asking about spectatorship.

xv Nothing relies on, or should be read into, my use of terms such as 'event' or 'occurrence' here. I simply need different words to distinguish between matches (which I'm calling events, because much of what is said here is relevant to other kinds of sporting event) and things that happen within an event, such as a particular tackle, penalty, display of skill etc. (which I'm calling occurrences). Occurrences will frequently be actions, but need not be (lightning striking the goalposts, or some seating collapsing for example).

xvi The lack of a finite totality is a feature of the occasion-sensitivity here. See McFee (2004) for the same thought in a number of different contexts.

xvii See Baker (2004: 43) on the connection here to Wittgenstein's use of the notion of perspicuous representation.

xviii The relevant essay is also published as Travis (2011a). Travis calls them 'true pictures of one phenomenon' but, following Baker, I'm not comfortable with the idea that pictures can be true or false, so prefer to think of them as being more or less appropriate, although that isn't the only way to think of them. For example, we might concentrate of their utility and consider them as more or less useful (for dissolving someone's philosophical puzzlement) in a specific context (appropriateness and utility are aspects of pictures!). The important thing to stress is the role of context in relation to appropriateness or utility.

xix It is worth making an observation about the asymmetry of the distinction between partisan and purist ways of watching sport. If we consider what it would be to be close to the pure forms of these ways of watching sport (to be at either end of Mumford's spectrum), then the partisan way of watching sport seems the more plausible of the two. It just isn't very easy to imagine someone always watching sport in the purist manner, yet it seems quite possible that someone might come close to always watching sport in a partisan manner.

xx Mumford (2012: 51) suggests otherwise, but that seems to be to confuse the scripted with metaphorical uses of the notion of an event being scripted in contexts where there is a structure and rules.

xxi I'm grateful to Graham McFee for raising this point.

xxii The absence of instrumental breaks in most early blues guitar recordings in the 1920s and 1930s is of aesthetic significance, but the decision to arrange the music that way was a practical one; recordings had to be short to fit on the record, given the limitations of early recording technology. The practical considerations dictated the temporal conditions for the possibility of creativity, but that doesn't seem a reason to treat time as an aesthetic concept.

xxiii One might also wonder whether the intellectual slides into the competitive in relation to tactics.

xxiv Someone might also wonder whether it is really the case that partisan = purposive and purist = aesthetic. The partisan isn't like the gambler. The gambler need not watch the game, and needn't even know the result. All that is important for the gambler is that there is a particular result. The partisan may want the same result, but to the partisan it will matter whether his or her team won by one goal or by three (if that matters to the gambler it is only because of the specifics of the bet). The partisan will want to see the victory, and if possible actually be present at the football ground to witness it. Equally, if the partisan misses the game, he or she will not simply want to know whether their team won or lost, but a whole range of details about how they won or lost. The partisan who misses a game will do everything possible to see the highlights on television that evening, whereas the gambler has no reason (qua gambler) to give the match another thought having established whether there are any winnings to collect. 
xxv This is usually shored up in psychological research by the idea of the implicit (implicit awareness, attention, decisions etc.). The issues raised by that idea would require a separate essay, but in this case it is sufficient to point out that recourse to the implicit won't do; the aesthete has to know that he or she appreciates something.

xxvi Mumford (2012a: 373) does say: 'This could, of course, itself be an oversimplification and I don't want to deny that there are any qualitative considerations. Time spent in aesthetic perception may not be the only factor. An experienced purist might be able to make deep and educated aesthetic judgments quickly and enjoy them immensely but I propose to go no further into this aspect of the aesthetic judgment itself.'

xxvii As Best (1978: 99) stresses, 'it is less conducive to error to regard the aesthetic as a way of perceiving an object or activity than as a constituent feature of it'. To recognize that is not to be blind to the fact that aesthetic judgement depends on objective features of the movement or object under consideration. See Best's distinction between the evaluative and conceptual use of 'aesthetic' and the implications of that distinction for how we understand the expression 'aesthetic content' (Best, 1978: 99-100).

xxviii The spectator who turns to a friend who supports the opposing team and stresses the beauty of a freekick may be doing so purely as an indirect means of stressing the superiority of his or her team. In other words, having considered the circumstances we might think that there isn't much in the way of appreciation of the beauty of the free-kick, just some kind of sophisticated bragging. So it isn't enough that the case be one that displays beauty; appreciation of the case would require more than simple reference to its beauty (say, for example, further discussion).

xxix See Baker (2004), Morris (2004; 2007).

xxx See McFee (1999) for a more detailed discussion of the unsuitability of aspect-perception as a model for artistic appreciation, and the actual role of Wittgenstein's remarks on aspect-perception as 'a device introduced as part of an argument against certain misconceptions; pictures of seeing, meaning and understanding (and their interconnections) that might generate confusion' (McFee, 1999: 283).

xxxi The idea of rapid switching (element vi of Mumford's picture) starts to appear unnecessary, given the remarks above about aspect-perception as a model for spectatorship. However, we might go a little further than that in pointing out that if aspect-perception seems to be a poor model for football spectatorship, then the idea of rapid switching loses its importance (which came from the model of aspect-perception). Also, rapid switching seemed relatively unproblematic if we accepted aspect-perception as a model for football spectatorship, but if we have reason to question the use of aspect-perception as a model in that context, then preservation of the notion of rapid switching without aspect-perception as our model for watching football seems more problematic. The examples of aspect-perception illustrate the possibility of rapid switching in very specific cases, but those cases seem very different from the kinds of cases we encounter in watching football. xxxii Contrary to (or at least a distinctly different conception from) element vii of Mumford's picture.

xxxiii Yet despite oscillation with varying degrees of rapidity, the suggestion is that it is still quantifiable. Consideration of just what oscillation with varying rapidity might amount to might raise doubts about whether it could all still be quantifiable. 